\title{
A study on malaria cases in hilly areas and Terai belt of Nepal
}

\author{
KRN Singh ${ }^{1}$, RB Sah ${ }^{2}$, PK Pokharel ${ }^{2}$ \\ Department of Internal Medicine ${ }^{1}$, Purbanchal University College of Medical \& Allied Sciences, Gothgaon, \\ Morang, Nepal, SPH \& CM, BPKIHS, Dharan, Nepal ${ }^{2}$
}

\begin{abstract}
Introduction: Malaria is a well-known disease and it continues to be a major public health problem at the start of new millennium. The problem is persistent not only amongst the city dwellers but also amongst the rural population. Objective: To identify the magnitude of malaria cases and to compare the malaria cases between hilly area and Terai belts. Methods: This cross-sectional study was carried out in Terai belt of Morang District Nepal at Nobel Medical College \& Research Center Biratnagar from March to Oct 2007 and hilly area around Lumbini Medical College Teaching Hospital \& Research Center Pravas, Tansen, Palpa of Nepal between March to December 2008. Blood samples were collected from all the cases and malaria parasites were examined by Peripheral Blood Smear Examination and Rapid Card Method Screening. Results: Thirty-five cases were malaria positive from hilly area of whom $80 \%$ had Plasmodium vivax infection. Whereas in Terai belt 231 positive cases ware recorded. Out of them (62.8\%) cases were affected by Plasmodium vivax infection. That most vulnerable age group was 15 years and above. Males were more affected than females. Conclusion: It was observed that in hilly areas the numbers of positive cases are less than the Terai belt. The magnitude of malaria cases are found high in July. A steady decline has been observed till September to October.
\end{abstract}

Key words: Hilly areas, malaria, peripheral blood smear, rapid screening test, Terai belt,

\section{Introduction}

According to the World Health Organization (WHO), malaria is the world's most important

\footnotetext{
Address for correspondence

Dr. Ram Bilakshan Sah

Assistant Professor

School of Public Health \& Community Medicine

B.P. Koirala Institute of Health Sciences, Dharan

E-mail: bilaksah@yahoo.com
}

parasitic disease, and it kills more people than any other communicable disease except tuberculosis. The disease is endemic in 100 countries and about 2 billion people (about $40 \%$ of the world's population) are at risk. ${ }^{1}$ Sub-Saharan Africa (SSA) is the most affected region where it is estimated that 
between 0.5 and 2 million people die annually from the disease. ${ }^{2}$ Malaria is caused by a protozoan parasite belonging to the genus Plasmodium and is transmitted through the bite of the Anopheline mosquito. Apart from the fact that malaria can be fatal, especially in children, it is a physically debilitating that imposes a high economic cost on the population. For example, the total treatment cost for an episode of malaria in the Kabale district in Uganda averaged around US\$9 for adults and US $\$ 4$ for children. ${ }^{3}$

There are many reports on relationship between density of a particular species of Anopheles or whole anopheline mosquitoes and malaria transmission cases in different parts of India. ${ }^{4-9}$ A relationship between $A$. maculatus catches and prevalence of malaria has been described by Rahman et $\mathrm{al}^{10}$ in Peninsular Malaysia. It is known that environmental factors including temperature and rainfall have a significant impact on the transmission of mosquito borne diseases as well as in the abundance of vectors. ${ }^{11}$ If a relationship between temperature/rainfall and mosquito abundance/malaria incidence is drawn in an area, it may become a possible predictor for forecasting the distribution of the disease.

This study is designed to identify the magnitude of malaria cases and to compatre the malaria cases between hilly area and Terai belt of Nepal.

\section{Methods}

The cross-sectional study was carried out in Terai belt of Morang District Nepal at Nobel Medical College \& Research Center Biratnagar from March to Oct 2007 and hilly areas around about Lumbini Medical College Teaching Hospital \& Research Center Pravas, Tansen, Palpa of Nepal between March to December 2008. Two hundred thirty one cases of villages of Terai belts coming to Nobel Medical College Teaching Hospital Biratnagar as OPD cases and indoor cases were recorded. Whereas 35 cases from hilly areas attending to Lumbini Medical College and Teaching hospital as OPD cases and indoor cases ware recorded. All the patients were recorded in as format age wise and sex wise. A separate format was made for month wise distribution of cases. Blood samples were collected from all the cases and malaria parasites were examined by Peripheral Blood Smear Examination and Rapid Card Method Screening.

\section{Peripheral blood smear examination}

A thin blood smear was prepared on a clean slide and after getting late air dried, 8 drops of Wright's stain was dropped and left for 1 to 2 minutes, then 16 drops of buffer was added to it and mixed intermittently by blowing and allowed to stain for 6-7 minutes then drained the stain and rinsed and washed in tap water. 
Then the slide was dried in the air and examined under oil immersion lens.

\section{Screening by rapid card method}

Brought the device to room temperature. Then $10 \mu$ of serum or plasma was added in the sample window and then 2 drops of buffer was added in the sample window. After 10 minutes the result was noted.

\section{Interpretation}

1. Only one colour band seen in the control region: test is negative
2. Two colour bands seen, one in the area $(\mathrm{Pv})$ and another in control region : test is positive for P. vivax (Pv)

3. Two colour bands seen: one in (Pf) region and other in control: test is positive for $P$. falciparum $(\mathrm{Pf})$

4. Three colour bands seen, one in control, one in $\mathrm{Pv}$ region and one is $\mathrm{Pf}$ region: test is positive for both $P$. vivax and $P$. falciparum.

5. No colour bands seen at all: test is invalid. Then repeat the test with new device.

\section{Results}

Table 1: Species wise distribution of malaria in hill and Terai

\begin{tabular}{|l|c|c|}
\hline \multicolumn{1}{|c|}{ Malaria cases } & $\begin{array}{c}\text { Total positive cases in } \\
\text { Pravas, Palpa }\end{array}$ & $\begin{array}{c}\text { Total positive cases in Morang, } \\
\text { Nepal }\end{array}$ \\
\hline Name of the species & $5(14.3)$ & $61(26.4 \%)$ \\
P. falciparum & $28(80.0 \%)$ & $145(62.8 \%)$ \\
P. vivax & $2(5.7)$ & $25(10.8 \%)$ \\
P. Mixed & $\mathbf{3 5 ( 1 0 0 . 0 \% )}$ & $\mathbf{2 3 1 ( 1 0 0 . 0 \% )}$ \\
\hline \multicolumn{1}{|c|}{ Total } & \multicolumn{2}{|}{} \\
\hline
\end{tabular}

It was observed that in hilly areas the numbers of positive cases are less than the Terai belt. In the present analysis 35 malaria positive cases from hilly areas were included who attended the outpatient department of Internal Medicine of Lumbini Medical College \& Teaching Hospital, Pravas, Tansen, Palpa. After investigations it was found that $80 \%$ cases had Plasmodium vivax infection,
(14.3\%) cases had Plasmodium falciparum infection and (5.7\%) cases had mixed infection.

Whereas in terai belts 231 positive cases ware recorded in Nobel Medical College Teaching Hospital, Biratnagar. Out of these $(62.8 \%)$ cases were Plasmodium vivax infection, (26.4\%) cases Plasmodium 
falciparum infections and (10.8\%) cases mixed infections.

Table 2: Distribution of malaria cases by age and gender

\begin{tabular}{|c|c|c|c|c|c|c|c|c|c|c|c|c|c|}
\hline \multirow{3}{*}{ Types of Malaria } & \multicolumn{13}{|c|}{ Age group and Gender } \\
\hline & \multicolumn{2}{|c|}{$\begin{array}{c}0-11 \\
\text { month }\end{array}$} & \multicolumn{2}{|c|}{$\begin{array}{l}1-4 \\
\text { yrs }\end{array}$} & \multicolumn{2}{|c|}{$\begin{array}{l}5-9 \\
\text { yrs }\end{array}$} & \multicolumn{2}{|c|}{$\begin{array}{c}10-14 \\
\text { yrs }\end{array}$} & \multicolumn{2}{|c|}{$\begin{array}{l}15+ \\
\text { yrs }\end{array}$} & \multicolumn{2}{|c|}{ Total } & \multirow[t]{2}{*}{ Grand Total } \\
\hline & $\mathbf{M}$ & $\mathbf{F}$ & $\mathbf{M}$ & $\mathbf{F}$ & $\mathbf{M}$ & $\mathbf{F}$ & $\mathbf{M}$ & $\mathbf{F}$ & $\mathbf{M}$ & $\mathbf{F}$ & $\mathbf{M}$ & $\mathbf{F}$ & \\
\hline \multicolumn{14}{|l|}{$\begin{array}{l}\text { Malaria cases } \\
\text { Pravas, Palpa }\end{array}$} \\
\hline Plasmodium vivax & 0 & 0 & 1 & 1 & 2 & 0 & 2 & 2 & 15 & 5 & 20 & 8 & $28(80.0 \%)$ \\
\hline $\begin{array}{l}\text { Plasmodium } \\
\text { falciparum }\end{array}$ & 0 & 0 & 0 & 0 & 0 & 0 & 0 & 0 & 4 & 1 & 4 & 1 & $5(14.3 \%)$ \\
\hline Plasmodium mixed & 0 & 0 & 0 & 0 & 0 & 0 & 0 & 0 & 1 & 1 & 1 & 1 & $2(5.7 \%)$ \\
\hline Total & 0 & 0 & 1 & 1 & 2 & 0 & 2 & 2 & 20 & 7 & 25 & 10 & $35(100.0 \%)$ \\
\hline \multicolumn{14}{|l|}{$\begin{array}{l}\text { Malaria cases } \\
\text { Morang, Terai } \\
\text { Belts }\end{array}$} \\
\hline Plasmodium vivax & 0 & 0 & 2 & 2 & 7 & 1 & 4 & 3 & 82 & 44 & 95 & 50 & $145(62.8 \%)$ \\
\hline $\begin{array}{l}\text { Plasmodium } \\
\text { falciparum }\end{array}$ & 0 & 0 & 4 & 0 & 3 & 2 & 4 & 1 & 25 & 22 & 36 & 25 & $61(26.4 \%)$ \\
\hline Plasmodium mixed & 0 & 0 & 1 & 0 & 2 & 0 & 2 & 0 & 14 & 6 & 19 & 6 & 25 (10.8\%) \\
\hline Total & 0 & 0 & 7 & 2 & 12 & 3 & 10 & 4 & 121 & 72 & 150 & 81 & 231(100.0\%) \\
\hline
\end{tabular}

M- Male, F- Female

It was found that most vulnerable age is 15 years and above and males are more affected than female.

Table 3: Month wise distribution of malaria cases pravas, Palpa

\begin{tabular}{|l|c|c|c|c|c|c|c|c|c|}
\hline Particular species & March & April & May & June & July & Augst & Sept & Oct & Total \\
\hline Plasmodium vivax & 2 & 4 & 1 & 2 & 15 & 1 & 2 & 1 & $28(80.0 \%)$ \\
\hline Plasmodium & 1 & 0 & 0 & 0 & 2 & 1 & 1 & 0 & $5(14.3 \%)$ \\
\hline
\end{tabular}




\begin{tabular}{|l|c|c|c|c|c|c|c|c|c|}
\hline falciparum & & & & & & & & & \\
\hline Plasmodium mixed & 1 & 0 & 0 & 0 & 1 & 0 & 0 & 0 & $2(5.7 \%)$ \\
\hline Total & 4 & 4 & 1 & 2 & 18 & 2 & 3 & 1 & $35(100 \%)$ \\
\hline
\end{tabular}

The magnitude of malaria cases are found high in July. A steady decline has been observed till September to October.

\section{Discussion}

Variation in the occurrence of the vector of malaria, which may be influenced both by the dry season and heavy rains, which might flush mosquito larvae from small streams. ${ }^{12,13}$ As expected, we found the lowest prevalence of malaria in the dry season. Numerous factors including the nature of the vector, amount of rainfall, and geographical characteristics help to establish this pattern of malaria prevalence.

In our study, total number of malaria cases are 231 in Terai belt of Morang District of Nepal at Nobel Medical College \& Research Center Biratnagar. Among them, P. vivax was $62.8 \%$, P. falciparum $26.4 \%$ and P. mixed $10.8 \%$. Total numbers of malaria cases are 35 in hilly areas around Lumbini Medical College Teaching Hospital \& Research Center Pravas, Tansen, Palpa of Nepal, among them $\mathrm{P}$. vivax was $80 \%$, P. falciparum $14.3 \%$ and P. mixed $5.7 \%$. So, total malaria cases are higher in Terai belts than hilly area but percentage of plasmodium is higher in hilly area than terai belts. In India, about $70 \%$ of the infections are reported to be due to $P$. vivax, $25-30 \%$ due to $P$. falciparum, $4-8 \%$ due to mixed infection and $1 \%$ due to $P$. malariae. ${ }^{14}$ The study conducted by Mishra et al showed high number of $P$. falciparum cases (59.09\%) was reported. ${ }^{15}$ Anand et al ${ }^{16}$ in a study at a secondary level hospital in Northern India noted that of the 41 cases 35 were positive for $P$. vivax and six were positive for $P$. falciparum. In a retrospective study conducted by Sidhu et al ${ }^{17}$ in Malaysia, a total of 64 cases were recorded, $50 \%$ of which were due to $P$. falciparum, $40.6 \%$ were due to P. vivax, $6.2 \%$ due to P. malariae and $3.1 \%$ due to mixed infection of $P$. falciparum and $P$. vivax.

It was found that most vulnerable age is 15 years and above and males are more affected than female which is similar in the study conducted by Mishra et al in Maharashtra, India showed adults are more vulnerable to disease in this area and the working group (20-40 yrs) are more affected due to malaria. ${ }^{15}$

Another study conducted by Khan $\mathrm{HU}$ in Pakistan showed out of 490 fever cases, 20\% were found positive for malaria, among them males $(76.53 \%)$ was found higher than and females $(23.46 \%)$ which is similar to this 
study. The average age of positive cases was 27.28 years, with an average age of 26.52 years in case of males and 29.86 for females. The predominance of males can be due to various factors. Males are the working and out going population in society, hence they have more chances of being bitten by infected mosquitoes. Also they have early and easy approach to the health care facilities as compared to females, because of our traditional hindrances for females in this respect. Among 75 male patients, 58.66\% were having $P$. falciparum, (40\%) P. vivax and only one (1.34\%) P. malariae infection. In 23 female patients, $56.52 \%$ were having $P$. falciparum and 10 (43.48\%) P. vivax. ${ }^{18}$ The study conducted by Sheikh et $\mathrm{al}^{19}$ in Quetta included all age group and range of 10-60 years showed the prevalence of malaria in febrile patients was $34.85 \%$. Prevalence of $P$. falciparum was 30.72 and $P$. vivex was $66.87 \%$ respectively in their study.

In this study, the magnitudes of malaria cases are found high in July. A steady decline has been observed till September to October. But in BHEL locality of Haridwar, a peak of malaria incidence was recorded in the month of September, indicating that malaria infection increased with the rise in density of mosquitoes in post monsoon season. ${ }^{20,21}$ In the vicinity of Nanak Matta Dam (Uttaranchal), higher malaria cases were encountered during October to December accompanied by increased density of $A$. fluviatilis. $^{22}$ However, they recorded the natural infection of sporozoites in the month of November.The distribution of mosquito was probably more governed by abiotic than the biotic factors. Of the possible abiotic influences on the transmission cycle of malaria, temperature and rainfall are the most important. In general, the water not only provides the medium for the aquatic stages of mosquito's life cycle but also increases the relative humidity and the longevity of adult mosquito. $^{23}$

In an area endemic for malaria in Bastar district, Madhya Pradesh, it was observed that A. fluviatilis fed throughout the year on man and was responsible for transmission of malaria from April to December. ${ }^{24}$ In our study malaria cases have been mostly recorded in July which may be due to seasonal activities of vectors as well as potential vector species favouring malaria transmission in the area.

Transmission of malaria is determined by many factors such as the vector abundance of the Anopheles mosquito species, the propensity and frequency of the mosquitoes to bite host, the longevity of mosquitoes, population immunity and the existence of malaria parasites as well as social factors like housing conditions and mosquito control measures. Rainfall influences transmission by 
its role in the life cycle while temperature acts as a regulatory force. ${ }^{25}$

\section{Conclusion}

It was concluded that in hilly areas the numbers of positive cases are less than the Terai belt. The most vulnerable age is 15 years and above, and males are more affected than female.The magnitude of malaria cases are found high in July and a steady decline has been observed till September to October.

\section{References}

1. World Health Organisation, WHO (1998) Malaria. WHO Fact Sheet No. 94. http://www.who.int/ctd/html/malaria.html . (Accessed on 14/06/2012)

2. Snow RW, Craig $M$, Deichmann $U$, Marsh K. Estimating Mortality, Morbidity and Disability Due to Malaria among Africa's Non-pregnant Population. Bulletin of the World Health Organisation 1999; 77(8): 624-640.

3. Lindblade KA, O'Neill DB, Mathanga DP, Katungu J, Wilson ML. Treatment for clinical malaria is sought promptly during an epidemic in a highland region of Uganda. Tropical Medicine and International Health 2003; 5(12): 865875.

4. Kulkarni SM. Density patterns of Anophelines and their relation to malaria in Bastar district, Madhya Pradesh. Indian J Malariol 1990; 27: 187-94.

5. Sharma SN, Subbarao SK, Choudhury DS, Pandey KC. Role of An. culicifacies and An. stephensi in malaria transmission in urban Delhi. Indian $\mathrm{J}$ Malariol 1993; 30: 155-68.

6. Dutta P, Dev V, Bhattacharrya DR. Anopheline fauna and malaria incidence in Changlang District (Arunachal Pradesh). Indian J Malariol 1993; 30: 135-43.

7. Tiwari. SN, Prakash A, Subbarao SK, Arti R, Joshi $H$, Sharma VP. Correlation of malaria endemicity with An. Culicifacies sibling species composition and malaria antibody profile in district Allahabad (U.P.). Indian $J$ Malariol 1994; 31: 48-56.

8. Hati AK, Chatterji KK, Biswas D. Some new approaches for determining critical density of Anopheles stephensi in Calcutta in relation to malaria transmission. J Parasit Appl Anim Biol 1992; 1: 71-5.

9. Dutta $P$, Bhattacharyya DR, Sharma CK, Dutta LP. Anopheline fauna of parts of Tirap district, Arunachal Pradesh with reference to malaria transmission. Indian J Med Res 1992; 95: 245-9.

10. Rahman WA, Hassan AA, Adanan CR. A relationship between Anopheles 
maculatus catches and the prevalence of malaria cases in an endemic village in peninsular Malaysia during 19901991. Trop Biomedicine 1994; 11: 107-9.

11. Peng BI, Tong S, Donald K, Parton KA, Jinfa NI. Climate variables and transmission of malaria: A 12-years data analysis in Shuchen County, China. Public Health Rep 2003; 118: 65-71.

12. Nakabayashi $T$, Tsukamoto $M$, Motomura I, Miyata A, Tsuneda K, Miyagig et al. Epidemiologic survey on malaria in some rural areas, especially in Palawan Island of the Philippines. Trop Med 1973; 15:154.

13. Ejercito A, Hess AD, Willard A. The sixyear Philippine-American malaria control program. Am J Trop Med Hyg 1954; 3:971.

14. Park K. Text book of preventive and social medicine. XVII edn (Nov) 2002; p. 193.

15. Mishra G.Hospital based study of malaria in Ratnagiri district, Maharashtra. J Vect Borne Dis 2003; 40: 109-111.

16. Anand K, Kant S, Kumar G. Clinical case definition of malaria at a secondary level hospital in northern India. Southeast Asian J Trop Med Pub HIth 1999; 30(2): 243-5.
17. Sidhu PS. NgSC: A retrospective study on malaria cases admitted to the University Hospital, Kuala Lumpur, 1984-1988. Med J Malaysia 1991; 46(2): 177-82.

18. Khan $\mathrm{HU}$, Khattak AM, Khan $\mathrm{MH}$, Mahsud IU, Shah SH. A study of prevalence of malaria in adult population of D. I. Khan, Pakistan. Biomedica 2006; 22:99-104.

19. Sheikh AS, Sheikh AA, Sheikh NS, Paracha SM. Endemicity of malaria in Quetta. Pakistan J Med Res 2005; 44: 41-5.

20. Chopra AK, Purushottam K. Malaria infection in and around BHEL locality of Hardwar. Him J Env Zool 1987; 1: 118-22.

21. Chopra AK, Purushottam K, Joshi BD. Annual trend of malaria infection in and around BHEL locality of Hardwar. Him J Env Zool 1988; 2: 45-9.

22. Shukla RP, Sharma SN, Kohli VK, Nanda N, Sharma VP, Subbarao SK. Dynamics of malaria transmission under changing ecological scenario in and around Nanak Matta Dam, Uttaranchal, India. Indian J Malariol 2001; 38: 91-8.

23. McMchael AJ, Martens WJM. The health impacts of global climate change: grasping with scenarios, predictive models and multiple uncertainties. Ecosystem Health 1995; 1:23-33. 
24. Kulkarni SM. Density patterns of Anophelines and their relation to malaria in Bastar district, Madhya Pradesh. Indian J Malariol 1990; 27: 187-94.

25. Devi NP, Jauhari RK. Relationship between Anopheles fluviatilis \& A.
Stephensi (Diptera: Culicidae) catches $\&$ the prevalence of malaria cases at Kalsi area in Dehradun district (Uttaranchal). Indian J Med Res 2006; 123:151-158. 